\title{
Effects of type of responding on memory/visual search: Responding just "yes" or just "no" can lead to inflexible performance
}

\author{
ARTHUR D. FISK \\ Georgia Institute of Technology, Atlanta, Georgia \\ and \\ PHILLIP L. ACKERMAN \\ University of Minnesota, Minneapolis, Minnesota
}

\begin{abstract}
Interactions of stimulus consistency and type of responding were examined during perceptual learning. Subjects performed hybrid memory-visual search tasks over extended consistent and varied mapping practice. Response conditions required subjects to respond to both the presence and absence of a target, only when a target was present or only when a target was not present. After training, the subjects were transferred to a different response condition. The results indicate that: (1) performance on search tasks with stimuli that are variably mapped show no qualitative changes attributable to manipulation of response format; (2) improvement due to consistent mapping (CM) practice is attenuated in the no-only response condition; (3) yes-only CM training attenuates the subjects' ability to transfer to no-only responding; and (4) yes/no CM training leads to the greatest improvement and transfer when compared with other responding conditions. The practice and transfer data support and extend previous research investigating effects of response set in memory/visual search and help to delineate factors that facilitate or inhibit reduction of load effects in memory and visual search.
\end{abstract}

One ubiquitous characteristic of human behavior, as it relates to the development of skills, is that performance improves with practice (cf. Newell \& Rosenbloom, 1981). Both the nature and the degree of improvement with practice, however, are dependent on how consistently subjects can deal with a task (Schneider \& Fisk, 1982). In visual and memory search paradigms, numerous studies have shown that extended consistent practice can lead to performance described as both qualitatively and quantitatively different from novice-level performance (e.g., Fisk \& Schneider, 1983; Fitts, 1964; Schneider \& Shiffrin, 1977).

The purpose of the present experiment was to determine how closely consistency must be tied to overt responding and how different classes of response requirements affect what is learned during consistent and varied memory search. Consistent mapping (CM) is used here

This research was conducted under Rome Air Development Center (RADC, Rome, New York) Contract F30602-81-C-0193 with SCEEE (Subcontract SCEEE-PDP/86-0069). The subcontract was funded with Air Force Human Resources Laboratory, LDIRP (Laboratory Director's Independent Research Program) funds. Yale Smith was the RADC sponsor and Michael Venturino was the AFHRL, Wright-Patterson, Ohio, contract monitor. The authors would like to thank Lester Krueger, Gordon Logan, and an anonymous reviewer for comments on an earlier version of the manuscript. Requests for reprints should be addressed to the first author at the School of Psychology, Georgia Institute of Technology, Atlanta, GA 30332. to refer to the training condition in which the target and distractor sets do not overlap; that is, the CM target-set items never appear as distractors. In varied mapping (VM) training conditions, the target and distractor stimuli are chosen randomly from the same set of characters over successive trials; that is, items from the VM set are used sometimes as targets and sometimes as distractors.

Several investigations have shown the importance of differentiating between CM and VM training (see Fisk, Ackerman, \& Schneider, in press, for a review). Early in practice, reaction time (RT) in both CM and the VM conditions increases as a function of memory-set or display size. The pattern of RTs suggests that subjects are performing a serial search through memory and/or the display. Late in practice (sometimes after thousands of practice trials), RT to CM stimuli is generally insensitive to increases in memory-set or display size. For CMtrained stimuli, the slope of the function relating memoryset size to RT is near zero, which suggests that the memory comparison is done in parallel (but see Townsend \& Ashby, 1983, for a further discussion of this issue). Extended practice has little effect on detection of VM-trained stimuli, that is, RT remains an increasing linear function of memory-set or display size.

It has been previously demonstrated that response requirements in memory scanning and visual search can have a profound impact on the standard set-size effect (that is, the effect of the number of items in the memory set 
on RT). Egeth, Marcus, and Bevan (1972) compared setsize effects when subjects were required to make ordinary yes/no responses (that is, push one button if the target appeared in the probe display and push a different button if the target did not appear in the probe display) with the set-size effects obtained when subjects were required to respond only when a target item was present ("yesonly'). Egeth, Marcus, and Bevan found that the magnitude of the set-size effect interacted with the response requirements. Subjects who were required to make both positive and negative responses exhibited longer positive trial comparison slopes than did subjects required to respond only when a target appeared $(45 \mathrm{msec} / \mathrm{item}$ vs. $0 \mathrm{msec} /$ item). Kristofferson (1975), noting that the Egeth, Marcus, and Bevan study used only a CM design, attempted to replicate the study using both a hybrid CM and a VM design. Kristofferson was able to find differences beween the one-response and the two-response conditions only for the hybrid CM condition; she reported no interaction between responding condition and set size when subjects participated in a VM search task.

Using a CM design, Egeth, Jonides, and Wall (1972) required one group of subjects to respond only when a target was present (yes-only) and another group of subjects to respond when a target was not present (no-only). Of interest for the current discussion are their Experiments 2 and 3. In Egeth, Jonides, and Wall's Experiment 2, memory-set size was always one item (and the target item never changed) and the number of elements to be searched in the probe display was varied from one to six items across trials. In that experiment, the no-only responders were about $100 \mathrm{msec}$ slower than the yes-only responders; however, the type of responding did not affect the comparison slope (near zero comparison slopes). In Experiment 3, Egeth, Jonides, and Wall required separate groups of subjects to respond to either the presence (yes-only) or the absence (no-only) of any digit in a background display of letters. In that experiment, memory-set size is hard to estimate but is probably greater than one, at least early in practice. Probe-frame size was varied from one to six items. With this manipulation, the yes-only responders showed a flat set-size effect (comparison slope of about zero), and the no-only responders performed more slowly as comparison load increased.

In summary, the literature suggests that the type of responding (positive only, negative only, or joint positive/negative) will influence performance in memory search tasks. Those effects seem limited to CM search. Consistent detection, with positive responding, seems to be necessary to produce substantial slope reductions in memory search. However, the generality of that previous research may be questioned because relatively limited practice was given to subjects. Furthermore, the previous research was not designed to simultaneously assess the effects of response type relative to one another and relative to both CM and VM search. Finally, there is in the literature no assessment of performance when subjects have been trained in one response condition and transferred to another condition (e.g., train in yes-only and transfer to no-only), which is an issue critical to eventual determination of the structure of learning under these various conditions. Related to this last issue, it has not been clear whether the performance differences resulting from various responding conditions are a matter of speed of learning or type of learning. Only by examining performance after extended practice and at transfer is it possible to begin to evaluate such differences.

Subjects in the present experiment were given extensive training in one of the three types of responding and then transferred to a different response condition. We assessed the effects of different response requirements by examining $\mathrm{CM}$ and VM memory search early in practice, after extended practice, and under transfer conditions. Current formal modeling efforts by Schneider (1985, 1987; Schneider \& Detweller, in press) suggest that no-only response training will lead to the least relative improvement during training. That model predicts that the relative change in "priority" between CM targets and VM distractors may be considerably reduced without positive response training. In addition, there are reasons to believe that response set may interact with practice and produce different degrees of transfer: Schneider and Fisk (1984) argued that experimental context was the major site of CM practice/transfer effects observed in their perceptual learning experiments. If consistent experimental context affects performance improvement and the ability to transfer what has been learned, then it can be predicted that transferring to a new, never-before-performed response (e.g., transferring from yes-only to no-only responding) will disrupt performance.

\section{METHOD}

\section{Subjects}

Forty students from the University of South Carolina were paid for their participation. All subjects were right-handed, reported English as their native language, and had normal or corrected-to-normal vision.

\section{Stimuli}

The target and distractor stimuli were chosen from a set of 10 uppercase letters (A, C, D, E, M, R, S, T, U, and Z). Each subject within a responding condition received a unique combination of these letters as CM and VM stimuli (counterbalanced by a partial Latin square); these letter combinations were duplicated across the responding conditions. Each subject was assigned three letters as a CM target set and seven letters as a VM set. The CM letters appeared as targets only in the probe display; the VM letters appeared as both targets and distractors and were used as distractors on the CM trials. The probe display consisted of two rows of two letters each, centered on the fixation point. The subjects sat approximately $71 \mathrm{~cm}$ from the display. Each letter was $.48 \mathrm{~cm}\left(.38^{\circ}\right)$ wide and $.65 \mathrm{~cm}\left(.53^{\circ}\right) \mathrm{high}$; the horizontal separation between letters in each row was $1.90 \mathrm{~cm}\left(1.53^{\circ}\right)$ and the vertical separation between the rows was $1.82 \mathrm{~cm}\left(1.46^{\circ}\right)$.

\section{Equipment}

The experiment was controlled using IBM PC/XT computers. The computers were programmed to present the appropriate stimuli, 
collect responses and latencies (in milliseconds), and control timing of the display presentation. Monochrome (green screen) monitors were used to display the stimuli.

\section{Procedure}

The task was a hybrid memory-visual search paradigm. The subjects were required to memorize one, two, or three letters (memory set) on each trial. The subjects could study the memory set for up to $30 \mathrm{sec}$. The subject initiated each probe display by pushing button " 3 "' (on the top row of the IBM PC keyboard) with the left index finger. After the buttonpress, a fixation dot was presented for $500 \mathrm{msec}$, followed by a probe display. The probe display consisted of four letters positioned to form a square around the central fixation dot. How the subject was to respond depended upon the response condition and whether or not an item from the memory set was present in the probe display. To illustrate, on a positive trial (memory-set item present in the probe display) with memoryset size of three, the subject might see the letters A, D, E, push the trial-initiation button, see the fixation dot, and then a probe display consisting of the letters $M, R, A, S$ positioned to form a square around the central fixation dot. Subjects in the yes/no and the yesonly responding conditions would push the "target present" button; subjects in the no-only responding condition would not respond. Similarly, if a memory-set item was absent from the probe display (a negative trial), subjects in the yes/no condition would push the "target absent" button; subjects in the yes-only condition would not respond; subjects in the no-only condition would push the response button. (All subjects were instructed to respond with the right index finger. Subjects in the yes/no responding conditions rested the right index finger between the " 9 " [target present] and " 0 " [target absent] keys. For the yes-only and the no-only conditions, the " 9 " key was used as the response button and subjects rested the right index finger on that key.)

Each subject was provided with three performance-feedback cues: an error tone was sounded on incorrect trials, and the subject's average RT (for correct trials) and average accuracy were displayed before each trial. The RT and accuracy feedback were reset to zero before each block of 30 trials.

\section{Design}

There were four independent variables: (1) the relationship between the target and distractor stimuli (either CM or VM), (2) memory-set size $(1,2$, or 3$)$, (3) target presence in the probe display (present or absent), and (4) the type of response training/transfer condition (see description below). Type of response training/transfer was manipulated between subjects; the other variables were manipulated within subject.

The two stimulus consistency conditions-CM and VM-were alternated between blocks of trials ( 30 trials per block). The probability of target presence on any trial was .50. Memory-set size was permuted randomly across trials with the restriction that, within a block, 10 trials occur for each memory-set size (five positive and five negative trials per memory-set size). The response conditions were: (1) standard yes/no responding (press one button if target present, press a different button if target absent); (2) yes-only (respond with button response only when a target present); (3) no-only (respond with buttonpress only when a target absent).

After training, the subjects were transferred to either yes-only or no-only responding. Thus, there were four training/transfer conditions: (1) yes/no response training, transfer to no-only responding; (2) yes/no response training, transfer to yes-only responding; (3) yes-only response training, transfer to no-only responding; and (4) no-only response training, transfer to yes-only responding. Ten subjects were assigned to each of the four response training/transfer conditions.

Before data collection began, the subjects were given 30 task trials for orientation. The subjects completed a total of $1,500 \mathrm{CM}$ trials and 1,500 VM trials. Following the training trials, the subjects were transferred to a different response condition, in which they completed a total of $150 \mathrm{CM}$ and $150 \mathrm{VM}$ trials. During transfer, the $\mathrm{CM}$ and VM conditions were also alternated between blocks of 30 trials. Each subject participated in one 50-min session per day and completed the experiment in 4 to 6 days. (The subjects were able to rest between blocks and were encouraged to do so if they found themselves getting fatigued. Since the rest times were self-paced, the subjects completed slightly different numbers of trials each session. This procedure was used to facilitate motivated, active participation by the subjects during task performance.)

\section{RESULTS}

The data were grouped into early practice (first $150 \mathrm{CM}$ and first $150 \mathrm{VM}$ trials), late practice (last $150 \mathrm{CM}$ and last $150 \mathrm{VM}$ trials), and transfer (all $150 \mathrm{CM}$ and 150 VM trials after transfer). Mean RT and comparison slope estimates were based on correct trials. RTs of less than $150 \mathrm{msec}$ or more than $4 \mathrm{sec}$ were considered error trials. Error rates were low (no subject exceeded $2.5 \%$ errors), and the errors did not vary systematically across conditions.

\section{VM Performance}

The VM RT data are plotted in Figure 1. The data are shown for the early, late, and transfer stages of the experiment. Data for each response training/transfer condition are shown in a separate panel of the figure. All conditions indicate the typical linear set-size effects normally observed in VM visual-search experiments (see Schneider \& Shiffrin, 1977). The linear set-size effect is apparent at all phases of the experiment (early, late, and transfer). The estimates of the comparison slopes (mean of the individual subjects' slopes) for the VM trials are provided in Table 1. Across the conditions, the comparison slopes range from 28 to $40 \mathrm{msec}$ for positive VM trials and from 39 to $66 \mathrm{msec}$ for negative trials. As expected, all of the VM positive and negative slope estimates statistically differed from zero. Comparisons among slopes early and late in practice showed that training had little or no effect on the VM slopes [all $F \mathrm{~s}<1$ except for positive trials in the yes/no $\rightarrow$ no-only condition, $F(1,18)=4.08$, and the no-only $\rightarrow$ yes-only condition, $F(1,18)=1.02$ ]. As would be expected, assuming self-terminating search, transfer from yes-only responding to no-only (yes-only $\rightarrow$ no-only) and transfer from no-only to yes-only (no-only $\rightarrow$ yes-only) altered the slopes $[F(1,18)=$ $12.56, p<.003$, and $F(1,18)=17.93, p<.0005$, respectively]. Transfer from yes/no responding to either yes-only or no-only responding did not change the slopes $\left(F_{\mathrm{s}}<1\right)$.

The overall picture that emerges from the VM data, which is important for providing the necessary baseline measures, is that the type of response training did not qualitatively affect VM search performance. Visual inspection of Figure 1 verifies the lack of a response condition effect (qualitative effect), as does the finding that the interaction between response condition and phase of 


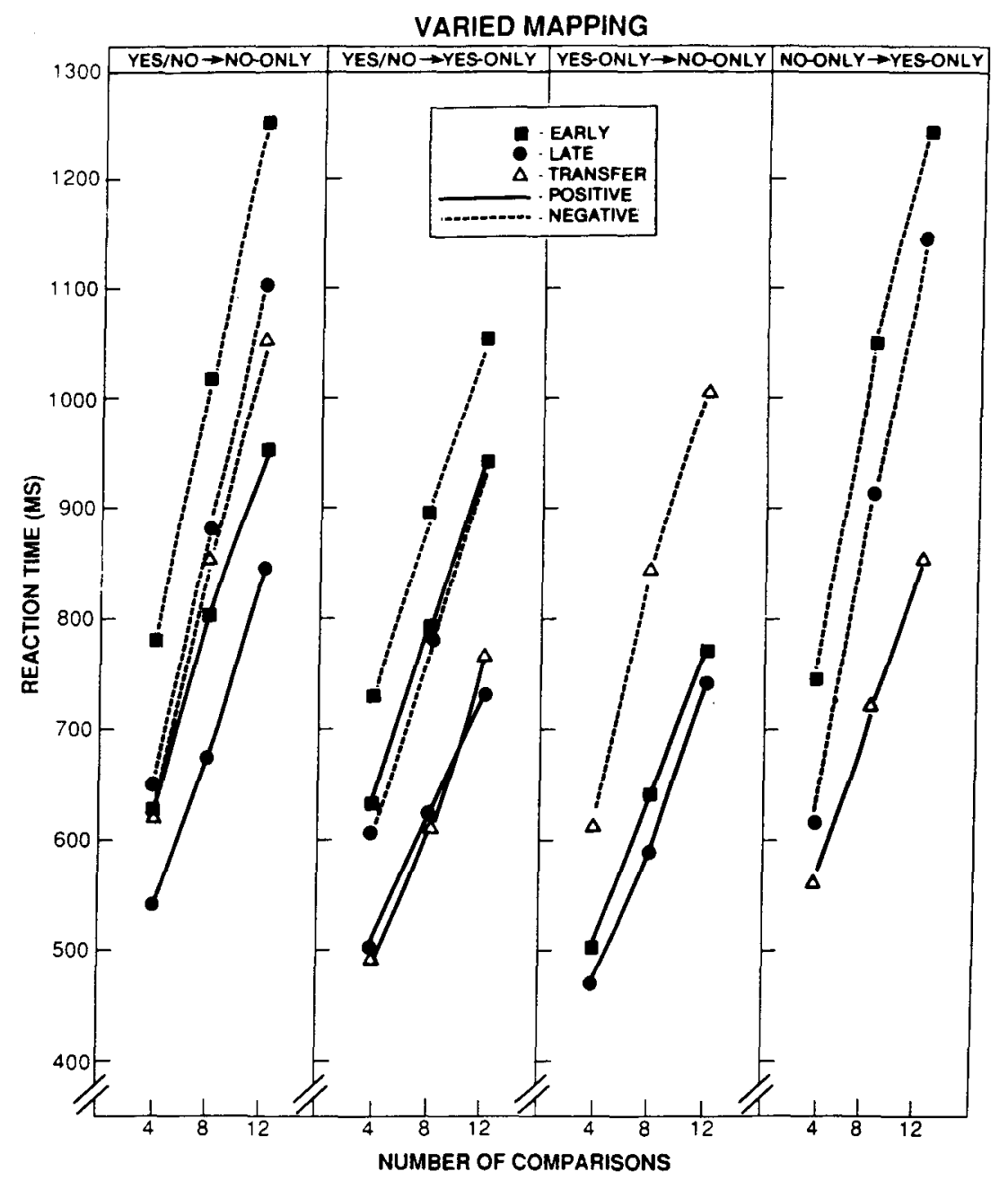

Figure 1. Varied mapping RT data. Data are presented in separate panels for each response training/transfer condition.

the experiment was nonsignificant $[F(3,36)=1.76$, $p>.05]$. As often is found with VM search, the trial type (positive vs. negative) did have an effect on the subjects' response times $[F(1,18)=114.85, p<.0001]$.

\section{Performance}

The relevant CM RT data, for all response training/transfer conditions, are presented in Figure 2. Each training/transfer condition is shown in a separate panel of the figure. Within each panel, performance early, late, and at transfer is shown. Across the CM training conditions, the RT data show different patterns of performance, dependent on the type of responding. The most striking contrast concerns the no-only response training (rightmost panel in Figure 2). The CM slope reductions were severely attenuated over practice for the subjects required to respond only to the absence of the CM targets (also see Table 1). Furthermore, this attenuation persisted at transfer. Although not statistically significant, the subjects trained with the no-only response were actually slower at the transfer phase of the experiment than the yes-only subjects were
Table 1

Comparison Slopes for VM and CM Responding Conditions

\begin{tabular}{|c|c|c|c|c|c|}
\hline \multirow[b]{2}{*}{ Trials } & \multirow{2}{*}{\multicolumn{2}{|c|}{$\begin{array}{c}\text { Training } \rightarrow \text { Transfer } \\
\text { Condition } \\
\end{array}$}} & \multicolumn{3}{|c|}{ Phase of Experiment } \\
\hline & & & Early & Late & Transfer \\
\hline \multicolumn{6}{|c|}{ VM Slope Estimates } \\
\hline Positive & $\begin{array}{l}\text { Yes/no } \\
\text { Yes/no } \\
\text { Yes-only } \\
\text { No-only }\end{array}$ & $\begin{array}{l}\rightarrow \text { No-only } \\
\rightarrow \text { Yes-only } \\
\rightarrow \text { No-only } \\
\rightarrow \text { Yes-only }\end{array}$ & $\begin{array}{c}40.62 \\
38.18 \\
33.78 \\
-\end{array}$ & $\begin{array}{c}37.92 \\
28.90 \\
33.74 \\
-\end{array}$ & $\begin{array}{c}- \\
34.72 \\
- \\
36.34\end{array}$ \\
\hline Negative & $\begin{array}{l}\text { Yes/no } \\
\text { Yes/no } \\
\text { Yes-only } \\
\text { No-only }\end{array}$ & $\begin{array}{l}\rightarrow \text { No-only } \\
\rightarrow \text { Yes-only } \\
\rightarrow \text { No-only } \\
\rightarrow \text { Yes-only }\end{array}$ & $\begin{array}{c}58.70 \\
39.65 \\
- \\
58.92\end{array}$ & $\begin{array}{c}56.46 \\
41.10 \\
- \\
65.97\end{array}$ & $\begin{array}{c}53.24 \\
- \\
62.00 \\
-\end{array}$ \\
\hline \multicolumn{6}{|c|}{ CM Slope Estimates } \\
\hline Positive & $\begin{array}{l}\text { Yes/no } \\
\text { Yes/no } \\
\text { Yes-only } \\
\text { No-only }\end{array}$ & $\begin{array}{l}\rightarrow \text { No-only } \\
\rightarrow \text { Yes-only } \\
\rightarrow \text { No-only } \\
\rightarrow \text { Yes-only }\end{array}$ & $\begin{array}{l}25.70 \\
26.56 \\
19.00 \\
-\end{array}$ & $\begin{array}{l}6.50 \\
7.40 \\
7.50 \\
-\end{array}$ & $\begin{array}{c}- \\
6.58 \\
- \\
18.10\end{array}$ \\
\hline Negative & $\begin{array}{l}\text { Yes/no } \\
\text { Yes/no } \\
\text { Yes-only } \\
\text { No-only }\end{array}$ & $\begin{array}{l}\rightarrow \text { No-only } \\
\rightarrow \text { Yes-only } \\
\rightarrow \text { No-only } \\
\rightarrow \text { Yes-only }\end{array}$ & $\begin{array}{c}31.66 \\
23.30 \\
- \\
36.43\end{array}$ & $\begin{array}{c}9.44 \\
9.58 \\
- \\
27.65\end{array}$ & $\begin{array}{c}8.01 \\
- \\
24.35 \\
- \\
\end{array}$ \\
\hline
\end{tabular}


CONSISTENT MAPPING

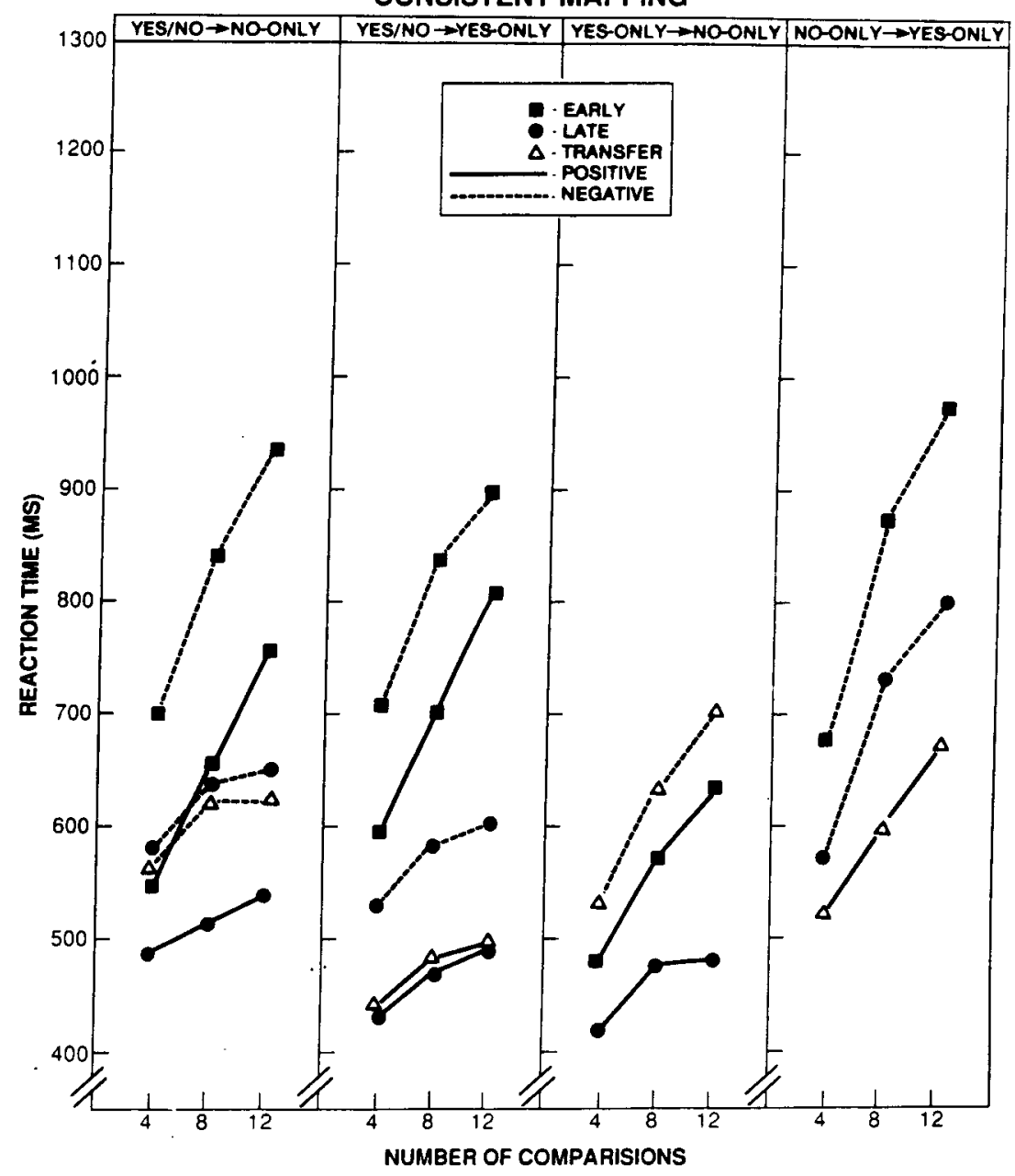

Figure 2. Consistent mapping RT data. Data are presented in separate panels for each response training/transfer condition.

early in the experiment $[F(1,18)=3.76, p=.068]$. Although the performance of subjects trained with the yes-only response was disrupted at the transfer phase, these subjects' yes-only $\rightarrow$ no-only transfer performance was faster than the late-in-practice RTs of subjects trained with the no-only response $[F(1,18)=5.47, p<.035]$.

Consistent with the findings of previous research, the CM RTs for the traditional yes/no response training condition significantly improved with practice $[F(1,9)=$ $20.25, p<.0015$, and $F(1,9)=25.93, p<.001$, for yes/no transferred to no-only and yes/no transferred to yes-only conditions, respectively]. The subjects' positivetrial RTs did not change when they transferred from yes/no responding to yes-only responding $(F<1)$; however, the negative-trial RT performance of subjects transferred from yes/no responding to no-only responding showed a small, but significant, improvement $[F(1,18)$ $=14.00, p<.002]$.
Considering RT data at the transfer phase of the experiment only, the yes/no response subjects who were transferred to yes-only responding (yes/no $\rightarrow$ yes-only) had significantly faster RTs than the no-only response subjects who were transferred to yes-only (no-only $\rightarrow$ yes-only) responding $[F(1,36)=5.61, p<.05]$. In contrast, there was no statistically significant difference in no-only transfer RTs when the yes-only and the yes/no trained subjects (yes/no $\rightarrow$ no-only vs. yes-only $\rightarrow$ no-only) were compared $[F(1,18)=2.26, p>.12]$.

The slope estimates for CM comparison times are given in Table 1. An examination of the slopes for early and late phases of the experiment shows that the no-only response training did not lead to a significant reduction in comparison slopes; all other CM late-training comparison slopes were not significantly different from zero. There was a significant effect of transfer for the yes-only subjects when transferred to no-only responding $[F(1,18)$ 
$=5.96, p<.03$ ]. For those subjects, transfer to no-only responding resulted in a linear relationship of RT to the number of comparisons and an increase in the comparison slope. Transfer from no-only responding to yes-only responding did not decrease the linearity of the set-size function, but did significantly reduce the comparison slope from 27 to $18 \mathrm{msec}$ per comparison $[F(1,18)=6.36$, $p<.025]$. Transfer had no effect on slopes for subjects receiving yes/no response training regardless of whether they were transferred to yes-only or to no-only responding.

\section{DISCUSSION}

The significance of this experiment is reflected in the ability to assess performance improvement and its transfer as a function of response requirements for both consistent and varied mapping search. The lack of qualitative effects across the response conditions for the VM trials replicates and extends the findings of Kristofferson (1975, Experiment 2). In that experiment, Kristofferson's subjects were trained for only approximately 150 trials per response condition and each subject participated in both yes-only and yes/no responding conditions. The present experiment extends the generality of Kristofferson's results by giving subjects more extensive VM training, by manipulating the response format between subjects, and by including a no-only response condition.

The CM data allow us to address the issue of what factors influence learning during $\mathrm{CM}$ training. Reduction in comparison load as a function of $\mathrm{CM}$ practice can, in some cases, be explained either by automatic categorization of the target set (Shiffrin \& Schneider, 1977, Experiment 2) or by automatic attention attraction (Shiffrin \& Schneider, 1977, Experiment 1). The present data offer additional evidence that categorization is not sufficient to account for many $\mathrm{CM}$ practice effects because categorization was possible in all response conditions.

The data showing positive transfer for subjects trained in the yes/no conditions, and either zero or negative transfer for subjects in both the yes-only and the no-only response training conditions, support the view that context is a critical factor in CM training. Schneider and Fisk (1984) proposed a context activation hypothesis as logically isolating the site of $\mathrm{CM}$ training effects in semantic category search and transfer to untrained exemplars of the trained CM categories. The present data are consistent with that view, and also suggest the importance of the interaction among control processes and automatic activation in determining successful skilled performance (cf. Logan, 1985).

For interpreting the transfer data, we propose a framework that is similar to that proposed by Schneider and Fisk (1984). That is, memory is assumed to be a large collection of interconnected nodes. These nodes are associated with varying strengths. Learning is reflected as the modification of the activation patterns between nodes. We assume a strengthening of coactive information; that is, information concurrently activated in short-term storage will be associatively strengthened. With sufficient coactivation, one node will more strongly activate nodes that were previously coactive than nodes that had not been coactively strengthened. We also assume that coactivation followed by inhibition of a given node will lead to increased inhibition between activated and inhibited nodes. In this framework, control processes can be used to temporarily inhibit activation (Schneider, 1985). Finally, following Schneider and Fisk (1984), we assume three classes of nodes: informational nodes (for present purposes, feature, letter, and response); control nodes (search for letters, motor priming, and inhibition of activations), and contextual nodes (activations due to the experimental situation).

During CM search training, the experimental context would facilitate consistent coactivation and result in a strengthening of links between the target letters and a response for the yes/no and yes-only response conditions. Conversely, experimental context would consistently inhibit links between target letters and the response node in the no-only condition. Therefore, although targets are indeed detected in the no-only condition, their occurrence does not lead to strengthening or target "accentuation" (Shiffrin \& Dumais, 1981). Consistent activation of CM target letters leads to fast "yes" responses for all subjects making "yes" responses, and, for the yes/no responders, a failure to find the target would default to an explicit "no" response (cf. Atkinson \& Juola, 1973). Experimental context would facilitate the development of consistent "no" responses in the latter case.

At transfer, the yes/no trained subjects demonstrated positive transfer inasmuch as they were able to use control processes to inhibit the now undesirable response (Logan \& Cowan, 1984). The control nodes could be set to not interfere with the desirable response (which is analogous to inhibiting a response to "brake" the car during a skid on ice or oil while maintaining the corrective steering response). However, when transferred to the opposite response, the yes-only and no-only trained subjects could inhibit the inappropriate response although they would not previously have associated the new response situation with a response; hence, those subjects would be required to rely on control processes (which is analogous to having learned to inhibit a "braking"' response but not to steer out of a skid).

The present issues and data also relate to the concept of training negative instances discussed within the training technology literature (e.g., see Merrill, 1983; Tennyson, Choa, \& Youngers, 1981; Tennyson \& Park, 1973). Some training technologists have argued that it is valuable to train "what the target concept is not" in order to maximize concept or procedural learning. Merrill points out that there is a substantial amount of research showing that, for concept learning, negative examples provided along with positive examples of the to-be-learned concept or procedure may provide a better training environment than would positive examples alone. Although our per- 
ceptual learning data do not completely support such notions, the fact that the subjects who received yes/no training were more flexible (i.e., could transfer to yes-only or no-only responding without deficit) argues that the suggestions of the training technologists should not be categorically dismissed.

\section{REFERENCES}

Atkinson, R. C., \& Juola, J. F. (1973). Factors influencing speed and accuracy of word recognition. In S. Kornblum (Ed.), Attention and performance $I V$ (pp. 583-612). New York: Academic Press.

EGETH, H., JoNIDES, J., \& WALL, S. (1972). Parallel processing of multielement displays. Cognitive Psychology, 3, 674-698.

Egeth, H., Marcus, N., \& Bevan, W. (1972). Target-set and responseset interactions: Implications for models of human information processing. Science, 176, 1447-1448.

Fisk, A. D., Ackerman, P. L., \& Schnelder, W. (1987). Automatic and controlled processing theory and its application to human factors problems. In P. A. Hancock (Ed.), Human factors psychology (pp. 159-197). Amsterdam: North-Holland.

Fisk, A. D., \& SCHNeIDER, W. (1983). Category and word search: Generalizing search principles to complex processing. Journal of Experimental Psychology: Learning, Memory, \& Cognition, 9, 177-195.

FITTS, P. (1964). Perceptual-motor skill learning. In A. W. Melton (Ed.), Categories of human learning (pp. 243-285). New York: Academic Press.

Kristofferson, M. W. (1975). On the interaction between memory scanning and response set. Memory \& Cognition, 3, 102-106.

LoGAN, G. D. (1985). Skill and automaticity: Relations, implications, and future directions. Canadian Jourmal of Psychology, 39, 367-386.

LOGAN, G. D., CowaN, W. B. (1984). On the ability to inhibit thought and action: A theory of an act of control. Psychological Review, 91, 295-327.

MerRILL, M. D. (1983). Component display theory. In C. M. Regeluth (Ed.), Instructional-design theories and models: An overview of their current status (pp. 279-333). Hillsdale, NJ: Erlbaum.

NeWell, A., \& Rosenbloom, P. S. (1981). Mechanisms of skill ac- quisition and the law of practice. In J. R. Anderson (Ed.), Cognitive skills and their acquisition (pp. 1-55). Hillsdale, NJ: Erlbaum.

SCHNEIDER, W. (1985). Toward a model of attention and the development of automaticity. In M. I. Posner \& O. S. Martin (Eds.), Attention and performance $X I$ (pp. 475-492). Hillsdale, NJ: Erlbaum.

SCHNEIDER, W. (1987). Connectionism: Is it a paradigm shift for psychology? Behavior Research Methods, Instruments, \& Computers, 19, 73-83.

SChNeIDer, W., \& Detweller, M. (in press). A connectionist/control architecture for working memory. In G. H. Bower (Ed.), The psychology of learning and motivation (Vol. 21). New York: Academic Press.

SChNEIDER, W., \& Fisk, A. D. (1982). Degree of consistent training: Improvements in search performance and automatic process development. Perception \& Psychophysics, 31, 160-168.

SCHNEIDER, W., FisK, A. D. (1984). Automatic category search and its transfer. Journal of Experimental Psychology: Leaming, Memory, \& Cognition, 10, 1-15.

SCHNEIDER, W., \& SHIFFrIN, R. M. (1977). Controlled and automatic human information processing: I. Detection, search, and attention. Psychological Review, 84, 1-66.

Shiffrin, R. M., \& Dumais, S. T. (1981). The development of automatism. In J. R. Anderson (Ed.), Cognitive skills and their acquisition (pp. 111-141). Hillsdale, NJ: Erlbaum.

ShIFFrin, R. M., \& SCHNEIDER, W. (1977). Controlled and automatic human information processing: II. Perceptual learning, automatic attending, and a general theory. Psychological Review, 84, 127-190.

Tennyson, R. D., Chon, J. N., \&oungers, J. (1981). Concept learning effectiveness using prototype and skills development presentation forms. Joumal of Educational Psychology, 73, 326-334.

TENNyson, R. D., PARK, J. (1973). Effect of negative instances in concept acquisition using a verbal learning task. Journal of Educational Psychology, 64, 499-505.

ToWNSEND, J. T., \& AshBY, F. G. (1983). Stochastic modeling of elementary psychological processes. New York: Cambridge University Press.

(Manuscript received March 23, 1987;

revision accepted for publication September 30, 1987.) 